\title{
QVoip - Uma ferramenta para o monitoramento da qualidade de ligações VoIP utilizando o modelo-E
}

\author{
Fabio Pessoa Nunes, Fabio Sakuray, Leonardo de Souza Mendes e Mario Lemes Proença Jr.
}

\begin{abstract}
Resumo- Os sistemas que utilizam VoIP são muito sensíveis a alguns fatores que se alteram de acordo com o grau de utilização das redes por onde eles trafegam. A ferramenta QVoip é capaz de realizar ligações VoIP e ao mesmo tempo medir a qualidade da voz percebida pelos usuários. Essa medida é obtida com utilização do modelo-E que utiliza os fatores da aplicação VoIP e variáveis da rede para avaliar a qualidade. Com essa ferramenta é possível analisar quais são os fatores que mais degradam a voz, além de dar base a projetistas para avaliarem se uma rede é adequada à utilização do VoIP.
\end{abstract}

Palavras-chave- VoIP, Modelo-E, QoS.

Abstract- The VoIP systems are very sensitive to some parameters that can change according with the utilization of network where they pass. The tool QVoip is capable to make VoIP calls and measure the voice quality. This measure is made with the utilization of E-model using factors from the VoIP application and variables from the network to evaluate quality. With this tool it is possible to analyze the factors that degrade the voice and help designers to evaluate if a network is good to VoIP.

Keywords- VoIP, E-Model, QoS.

\section{INTRODUÇÃO}

A utilização da telefonia através da Internet vem despertando interesse devido a uma série de vantagens em relação à PSTN (Public Switched Telephone Network). Esse sistema de telefonia, também conhecido como Voz sobre IP (VoIP) tem se mostrado como uma alternativa viável ao sistema tradicional de telefonia, contudo em algumas situações ele não é capaz de garantir ao usuário uma qualidade comparável à telefonia convencional, devido a fatores que a rede pode apresentar, como perdas de pacotes e atrasos. Tais problemas ou falhas em um sistema de comunicação por voz podem tornar a conversação entre usuários desagradável e até impraticável.

Com o objetivo de analisar a qualidade do áudio que o usuário está recebendo durante uma chamada VoIP, várias medidas de qualidade foram normatizadas $[1,2]$, onde de acordo com informações da aplicação VoIP e da rede é

Fabio Pessoa Nunes e Leonardo de Souza Mendes, Departamento de Comunicações, Faculdade de Engenharia Elétrica e Computação, Universidade Estadual de Campinas, São Paulo, Brasil, E-mails: fpnunes@decom.fee.unicamp.br, lmendes@decom.fee.unicamp.br.

Mario Lemes Proença Jr. e Fabio Sakuray, Departamento de Computação, Universidade Estadual de Londrina, Paraná, Brasil, E-mails: proenca@uel.br, sakuray@uel.br. avaliada se a qualidade de serviço está aceitável durante a ligação. Esse trabalho apresenta a ferramenta QVoip que se destina a avaliar a qualidade de ligações VoIP utilizando o modelo-E [3], padronizado pelo ITU-T (International Telecommunication Union - Telecommunication Sector). Esse modo de avaliação das ligações foi utilizado para o desenvolvimento de uma ferramenta usada para avaliar vários cenários de redes, comparando os mesmos, validando o método de avaliação utilizado e verificando como os fatores da rede podem afetar ligações VoIP.

Este artigo está organizado da seguinte forma: Na seção 2 serão apresentados alguns trabalhos relacionados que também se utilizam de medidas de qualidade de ligações VoIP. A seção 3 apresenta como é realizado o cálculo da medida de qualidade utilizando o modelo-E, demonstrado como esse trabalho foi desenvolvido. Na seção 4 são apresentados os testes realizados e os resultados obtidos. A conclusão do trabalho desenvolvido será apresentada na seção 5.

\section{TRABALHOS RELACIONADOS}

Os trabalhos de avaliação de qualidade são divididos em dois grupos: avaliação subjetiva e avaliação objetiva. Na avaliação subjetiva um grupo de usuários atribui notas a uma amostra de som e a média dessas notas representa a qualidade do sistema em avaliação. Entre os métodos subjetivos mais conhecidos tem-se o MOS (Mean Opinion Score) [4] que é muito utilizado na avaliação de codecs e equipamentos VoIP. Já na avaliação objetiva são analisados os fatores do meio de transmissão de dados e características dos equipamentos, atribuindo notas referentes à qualidade. Entre os métodos objetivos temos o PSQM (Perceptual Speech Quality Measure) [5], PESQ (Perceptual Evaluation of Speech Quality) [6] e o Modelo-E.

Assim como no QVoip, em [7] é implementada uma ferramenta de monitoramento baseada em uma extensão do modelo-E proposta em [8], apresentando algumas correções a esse cálculo. Foi desenvolvida uma ferramenta para avaliar a qualidade do VoIP utilizando número variado de usuários entre a Universidade Federal de Manaus e a Universidade Federal do Ceará utilizando o backbone da RNP2. Tais testes mostraram que mesmo com uma rede de alto throughput, a qualidade decai com o aumento de ligações simultâneas.

Em [9] o modelo-E é utilizado para avaliar redes 802.11, porém como o meio sem fio não provê segurança aos dados transmitidos, é analisado o VoIP acrescentado de mecanismos de segurança como VPN e IPSec. Os autores analisam como a segurança e a criptografia de pacotes de voz altera a qualidade percebida pelo usuário e qual é o número aceitável de hosts utilizando a rede sem fios ao mesmo tempo. Eles mostram que há uma penalidade na qualidade 
devido ao acréscimo de segurança, provavelmente devido ao gasto de tempo com a criptografia dos dados.

Em [10] são avaliados os efeitos do tamanho de um pacote na qualidade de voz. Nesse trabalho foi utilizado um método conhecido como PESQ, que avalia o VoIP apresentando uma nota em MOS. Essa nota é transformada no tipo de nota do modelo-E, o fator R. A partir dessa nota, foi possível calcular algumas variáveis do modelo-E, como o $I e$, que geralmente são padronizadas pelo ITU-T, permitindo que se obtenham valores mais fiéis a essas variáveis de acordo com o codec utilizado. Com esses valores referentes ao codec foi possível realizar os testes que comprovaram que com o aumento do tamanho dos pacotes, uma perda representaria uma degradação superior na qualidade do que se fossem utilizados pacotes menores.

A variação do atraso sofrido pelos pacotes (jitter) é um dos principais agravantes de aplicações de voz. Para amenizar esse problema os aplicativos VoIP utilizam um buffer na saída de reprodução do que está sendo recebido, porém uma das maiores dúvidas é sobre qual é o tamanho ideal desse buffer. K. M. McNeill et al. [11] elabora um método adaptativo de definir o tamanho do buffer de jitter em redes wireless. Este método avalia as condições da rede e define o tamanho do buffer que proverá uma melhor qualidade ao usuário. Segundo testes utilizando o modelo-E realizados pelos autores, esse método proposto melhora de $11 \%$ a $15 \%$ a qualidade do VoIP em comparação com outros algoritmos adaptativos.

Nesse trabalho temos como objetivo avaliar ligações VoIP utilizando o modelo-E em diferentes redes e em diversas situações, demonstrando os fatores mais degradantes e as situações em que a Voz sobre IP é menos aconselhável.

\section{O MODELO-E E A FERRAMENTA QVOIP}

Com o objetivo de avaliar o comportamento de ligações VoIP, é apresentada uma ferramenta, denominada QVoip, para analisar a qualidade do som recebido pelos usuários durante uma chamada. O QVoip é um aplicativo VoIP que tem a capacidade de realizar chamadas telefônicas através da rede de dados e ao mesmo tempo capturar dados da rede para avaliar a qualidade do áudio recebido pelo usuário. Ele servirá como ferramenta para analisar em tempo real se uma rede é adequada à utilização de aplicações de comunicação de voz, além de prover ao usuário um meio de validar se o serviço de VoIP contratado está atendendo ao que foi proposto pela empresa contratada. Para elaborar a ferramenta proposta, foi incorporado ao software Linphone [12] todos os cálculos necessários para avaliar a qualidade da ligação VoIP.

Com base em vários trabalhos [2,13,14], o modelo-E se mostrou ser a recomendação mais indicada para realizar essa avaliação, já que ele permite que a qualidade seja medida em tempo real pela aplicação de Voz sobre IP. Este método realiza cálculos com os fatores que afetam a qualidade do VoIP e apresenta uma nota, nomeada fator $\mathrm{R}$, que consiste em um valor variando de 0 a 100 , onde 100 representa uma alta qualidade e 0 uma péssima qualidade. A recomendação ITU-T G.107 [3] define que a utilização do modelo-E segue a equação (1).

$$
R=R 0-I S-I d-I e f+A
$$

Onde $R O$ representa a relação sinal/ruído, incluindo ruídos do circuito e do ambiente externo. O IS expressa a combinação de todo defeito que ocorre simultaneamente ao sinal de voz. O fator $I d$ representa os defeitos causados pelo atraso fim-a-fim. O Ief expressa os defeitos causados por características do equipamento, como o codec. E $A$ representa um fator de vantagem usado para compensar algumas falhas previstas.

A recomendação ITU-T G.107 apresenta expressões matemáticas e valores padrão para determinar a relação sinalruído. Por isso, de acordo com Lustosa [14], o valor padrão de $R O$ será 92,77. O autor também afirma que o valor de $I S$ pode ser padronizado de acordo com a mesma recomendação, estabelecendo o valor 1,41 para essa variável. Por último, o valor de $A$ foi definido em 0 , valor recomendado pela especificação do modelo-E para ligações VoIP.

Assim, segundo Lustosa et. al. [15], a equação do modelo-E pode ser reduzida a equação (2).

$$
R=93,36-I d(T a)-I e(c o d e c, \text { perda })
$$

Onde $I d(T a)$ é relacionado ao atraso fim-a-fim da rede, ou seja, o tempo em que a voz leva para sair da boca de um usuário e chegar ao ouvido de outro, e Ie(codec, perda) é uma função dependente do codec utilizado e da taxa de perda de pacotes.

Segundo Lustosa [14], Id (Ta) pode ser obtido pela equação (3).

$$
\begin{aligned}
& \text { Se }(T a \leq 177,3): \\
& I d(T a)=0,024 * T a \\
& \text { Se }(T a>177,3): \\
& \text { Id }(T a)=0,134 * T a-18,103
\end{aligned}
$$

Para calcular o valor de $T a$ representado na equação (3) é utilizada a equação (4).

$$
\text { Ta }=\text { Tcodec }+ \text { Trede }+ \text { Tbuffer }
$$

Tcodec representa o atraso inerente ao codec utilizado, valor que pode ser encontrado na norma ITU-T G.114 [16]. Já o Trede expressa o atraso (em ms) sofrido pelos pacotes de voz para percorrer a rede da origem até o seu destino. Por fim, o Tbuffer indica o atraso adicionado pelo buffer de compensação de jitter (em ms).

O valor de Ie(codec, perda) presente na equação (2) pode ser obtido pela equação (5), conforme também foi descrito por Lustosa [14].

$$
I e(\text { codec }, \text { perda })=I e+\frac{(95-I e) * P P L}{(P P L+B P L)}
$$

Ie representa o fator de perda associado ao equipamento, valor que pode ser obtido na especificação ITU-T G.113 
Appendix I [17]. Já o PPL indica a porcentagem de perda de pacotes no período em que se está medindo a qualidade, valor que deve ser medido na saída do buffer de jitter da aplicação. Finalmente, o $B P L$ expressa o fator de robustez à perda de pacotes referente ao codec, que pode ser encontrado para alguns codecs em $[17,18]$.

Algumas das variáveis apresentadas pelo modelo-E são relacionadas às escolhas realizadas pela aplicação VoIP durante a sua utilização. $O$ codec tem influência sobre algumas das variáveis desse método de avaliação, o que implica na necessidade de analisar qual codec é mais apropriado ao ambiente de rede utilizado. Além do codec, outro fator referente à aplicação é o tamanho do buffer de jitter, que adiciona atraso aos pacotes. Muitas vezes o tamanho desse buffer é fixo, entretanto alguns trabalhos, como o de McNeill et. al. [11], propõem modos de deixar esses tamanhos variando conforme a necessidades da rede. Como o objetivo desse trabalho é analisar os fatores da rede que degradam a qualidade da voz, foi fixado nessa aplicação a utilização do codec G.711, também conhecido como PCM, e o tamanho do buffer de jitter em $30 \mathrm{~ms}$.

Como podemos perceber temos duas variáveis do modelo-E que estão ligadas diretamente à rede e necessitando informações do estado da rede para obter o valor das mesmas. Uma dessas variáveis é o Trede que é o tempo que um pacote leva para atravessar a rede até o seu destino, e também pode ser definido como o atraso que o pacote de voz sofre na rede. Não há um modo preciso de medir o valor dessa variável, já que é muito difícil manter dois hosts distintos com os seus relógios sincronizados. Por isso, foi utilizado um modo definido por Schulzrinne et. al. [19] que obtém uma aproximação aceitável desse valor. Aplicações de voz em redes de dados necessitam trocar informações entre os participantes para saberem como a ligação está se comportando. Os pacotes RTCP se encarregam dessa função, já que esses pacotes são trocados pelos hosts da ligação de tempos em tempos. Então é possível utilizá-lo para medir o atraso sofrido por um pacote em uma rede. Em intervalos de tempo fixos a aplicação VoIP de um dos hosts envia ao outro usuário da chamada um pacote RTCP do tipo Sender Report (SR) que entre outras informações contém o timestamp do momento que esse pacote está sendo enviado. Ao chegar ao seu destino esse pacote é processado pelo host e o mesmo envia como resposta um pacote RTCP do tipo Receiver Report (RR) para o outro host contendo o timestamp que estava no SR e o tempo que foi gasto no processamento do SR nesse host. Quando o RR atinge o host que enviou o SR, a aplicação calcula o timestamp atual daquela máquina e subtrai do timestamp recebido com o RR, além de subtrair o tempo de processamento do SR no outro host. Assim, encontra-se o tempo que um pacote está levando para atravessar a rede e voltar para o mesmo host, o RTT (Round Trip Time). Para obter o tempo aproximado que o pacote leva para atravessar a rede é possível dividir o RTT pela metade, encontrando um valor que se aproxima do atraso que um pacote sofre para atravessar a rede para encontrar o outro host.

Outra variável fundamental nesse modelo é a porcentagem de perda de pacotes, o PPL. Perder um pacote não significa apenas o pacote não atingir seu destino, sendo descartado em algum lugar da rede. Também podem ser considerados como pacotes perdidos aqueles que chegam atrasados ao destino, mas não chegam à tempo de serem processados pela aplicação. De acordo com Carvalho et. al. [7], a perda de pacotes só pode ser medida no nível da aplicação, já que ela fará o processamento final dos pacotes e saberá se algum pacote não atingiu o destino. Tal verificação da perda de algum pacote é realizada verificando pelo número de seqüência dos pacotes se falta algum pacote no momento em que eles serão processados para gerar o som transportado pelos mesmos. O local dessa verificação é a saída do buffer de jitter da aplicação VoIP, já que esse buffer se destina atrasar alguns instantes a reprodução dos pacotes para que pacotes com um pouco de atraso tenham a chance de chegar na aplicação a tempo de serem reproduzidos.

Apesar dessas variáveis se alterarem constantemente, foram definidas algumas faixas desses valores que são aceitáveis para o VoIP. De acordo com a norma ITU-T G.114 [16], o atraso fim-a-fim em uma direção não deve ser maior que $150 \mathrm{~ms}$ para manter uma alta qualidade e atrasos acima de $400 \mathrm{~ms}$ são inaceitáveis para a maioria das redes. Em relação à perda de pacotes, cada codec aceita uma faixa de perda de pacotes, sendo que a variável BPL indica se o codec aceita um número de perdas muito elevada. $\mathrm{O}$ codec $\mathrm{G} .711$ é considerado um dos de melhor qualidade e que sofre menor influência na perda de pacotes.

O ITU-T relaciona em [20] algumas faixas de valores do fator $\mathrm{R}$ com a satisfação dos usuários do sistema. Essa comparação pode ser vista da tabela 1 .

TABELA 1

Definição de categorias de qualidade de transmissão de voz

\begin{tabular}{|c|c|c|}
\hline Fator R & $\begin{array}{c}\text { Qualidade } \\
\text { da } \\
\text { transmissão }\end{array}$ & Satisfação dos usuários \\
\hline $90<\mathrm{R} \leq 100$ & Melhor & Muito satisfeitos \\
\hline $80<\mathrm{R} \leq 90$ & Alta & Satisfeitos \\
\hline $70<\mathrm{R} \leq 80$ & Média & Alguns usuários insatisfeitos \\
\hline $60<\mathrm{R} \leq 70$ & Baixa & Muitos usuários insatisfeitos \\
\hline $50<\mathrm{R} \leq 60$ & Pobre & Quase todos usuários insatisfeitos \\
\hline
\end{tabular}

Com a escolha do Linphone e depois de uma análise mais aprofundada do modelo-E, foi possível incorporar o modeloE ao aplicativo VoIP, realizando algumas alterações ao software para captar as informações da rede necessárias na avaliação da qualidade. O cenário VoIP básico utilizado neste trabalho e as variáveis presentes no modelo-E podem ser observadas na figura 1. A figura demonstra que a maioria das variáveis do modelo-E está relacionada ao software VoIP, como o BPL, Ie e atraso do codec. Já a perda de pacotes está relacionada à rede, mas também é medida na aplicação. E por fim, o atraso da rede é calculado através do cálculo do RTT, que é obtido pelos pacotes RTCP. 


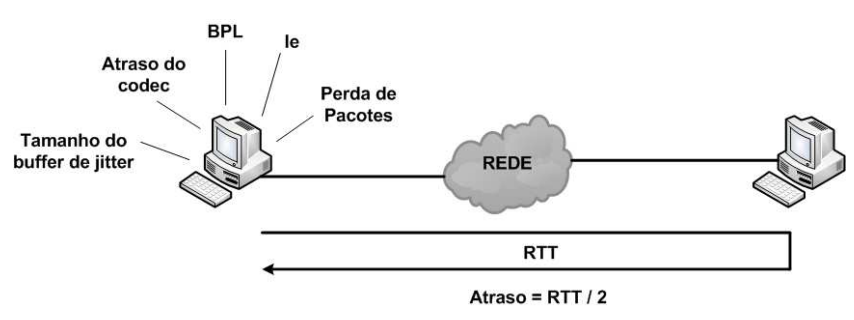

Fig. 1. Cenário VoIP e as variáveis do modelo-E

\section{RESULTADOS OBTIDOS}

Os testes foram realizados em dois cenários reais de rede com objetivo de calcular o fator R. Durante um período de 24 horas a ferramenta QVoip foi utilizada para realizar chamadas a cada 15 minutos e com duração de 5 minutos. No decorrer dessas chamadas foi medida, pelo host de origem e de destino, a qualidade percebida utilizando as variáveis necessárias para o cálculo do modelo-E.

A figura 2 ilustra o resultado do fator $\mathrm{R}$ avaliada pela ferramenta QVoip durante uma chamada em um dos cenários testados. Nela pode ser observado como a qualidade varia durante uma chamada de 5 minutos. Cada uma dessas medidas indica a qualidade da chamada VoIP que um usuário estaria presenciando naquele momento. O QVoip foi configurado para obter 14 medidas de qualidade em uma ligação de 5 minutos, entretanto o relatório final de qualidade pode conter um número menor de notas, já que quando um dos pacotes RTCP é perdido não será possível o cálculo do atraso naquele instante, não possuindo novos dados para o cálculo da qualidade. Cada chamada realizada é representada por uma nota do fator $\mathrm{R}$, que é obtida com o cálculo da média aritmética de todas as notas obtidas durante a ligação.

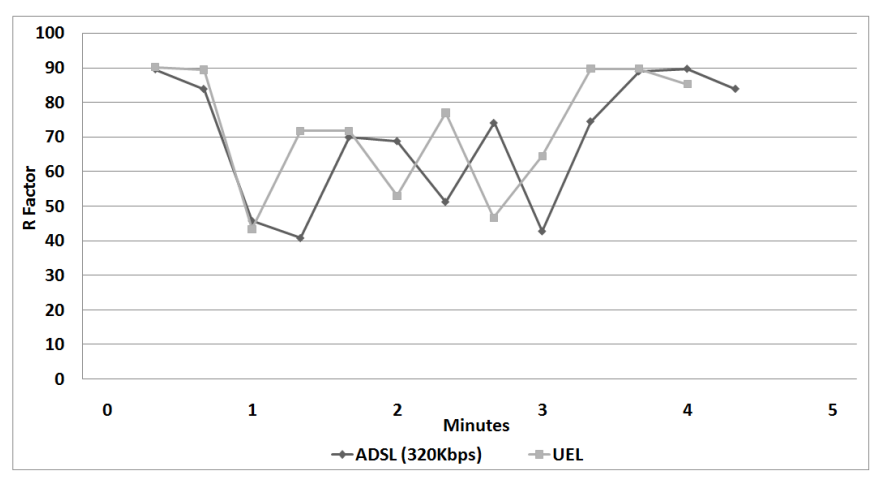

Fig. 2. Medida de qualidade de uma ligação

Nos dois cenários de testes, o equipamento de origem da chamada estava situado na Universidade Estadual de Londrina (UEL). Como o segmento de saída da rede da UEL com a Internet é utilizado por aproximadamente 5000 computadores, existem períodos de picos de utilização que resultam em momentos em que não é possível obter boa qualidade nas ligações VoIP devido ao excesso de tráfego no link de saída para Internet. Nos dias úteis de trabalho normais na Universidade tem-se uma utilização mais acentuada de download durante o período das 08h00min até aproximadamente $22 \mathrm{~h} 00 \mathrm{~min}$ e uma baixa utilização nos outros momentos, como pode ser observado no gráfico da figura 3, que representa a utilização do link para acesso à Internet da UEL.

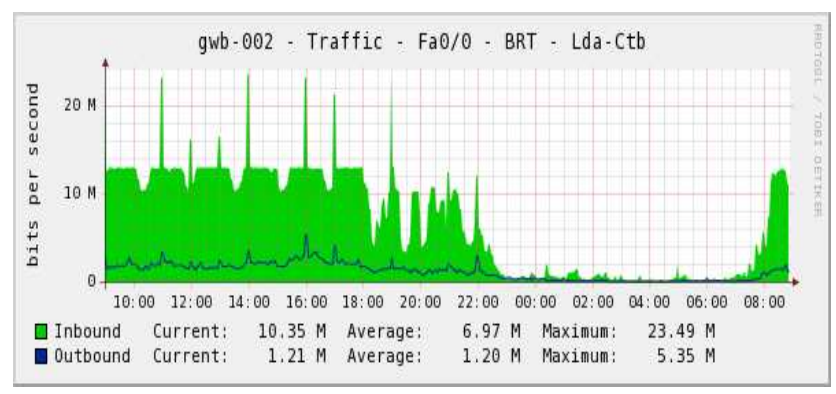

Fig. 3. Utilização do link de Internet da UEL

O primeiro cenário de testes foi realizado entre a UEL e uma conexão de Internet ADSL de $320 \mathrm{kbps}$ na mesma cidade da universidade. Durante o período de testes, como pode ser observado na figura 4, foi possível comprovar que nos períodos de maior utilização da Internet a qualidade percebida pelo usuário sofre mais alterações, sendo que em alguns momentos se aproxima de um cenário impróprio para a utilização do VoIP. Conforme foi apresentado na figura 3, a utilização maior do acesso à Internet se inicia aproximadamente às $08 \mathrm{~h} 00 \mathrm{~min}$, mesmo momento em que é possível observar que a qualidade da voz começa a sofrer variações, como ilustra a figura 4. Essa variação da qualidade, mesmo não sendo tão significativa em alguns momentos, continua durante todo o dia até aproximadamente às $22 \mathrm{~h} 00$ min, quando a utilização do link volta para níveis mais baixos.

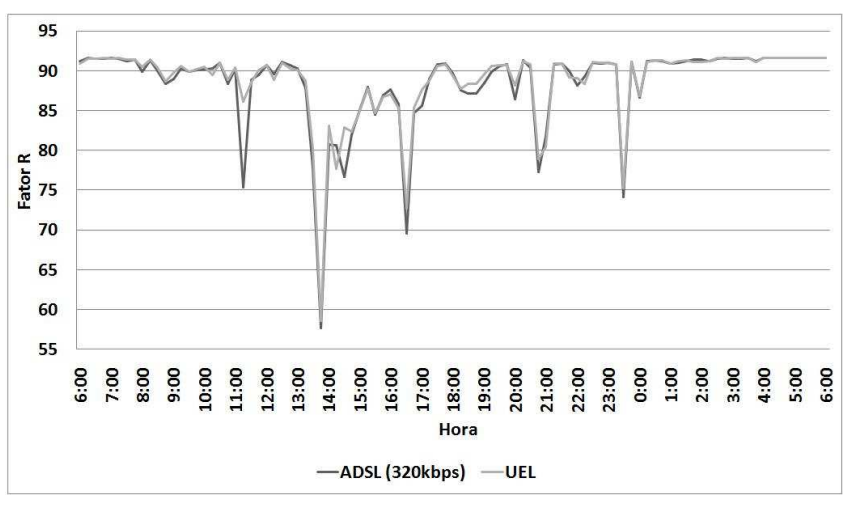

Fig. 4. Qualidade do VoIP entre a UEL e uma conexão ADSL

A figura 5 ilustra o gráfico do atraso médio entre a UEL e o ADSL durante todo o dia. Observa-se que durante o período de pouco utilização da Internet o atraso varia pouco. Entretanto, nos horários de pico existe uma grande variação, atingindo valores altos de atraso em alguns instantes. Comparando esse gráfico com o gráfico de qualidade da figura 4 , temos que nos momentos de baixa qualidade os atrasos são mais significativos. Essa comparação revela que o atraso tem uma grande influência na qualidade de ligações VoIP. No momento de pior qualidade do dia, às $13 \mathrm{~h} 45 \mathrm{~min}$, 
obteve-se o maior atraso na rede do período, sendo de 370,31 ms para o usuário do ADSL e 371,44 ms para o da UEL.

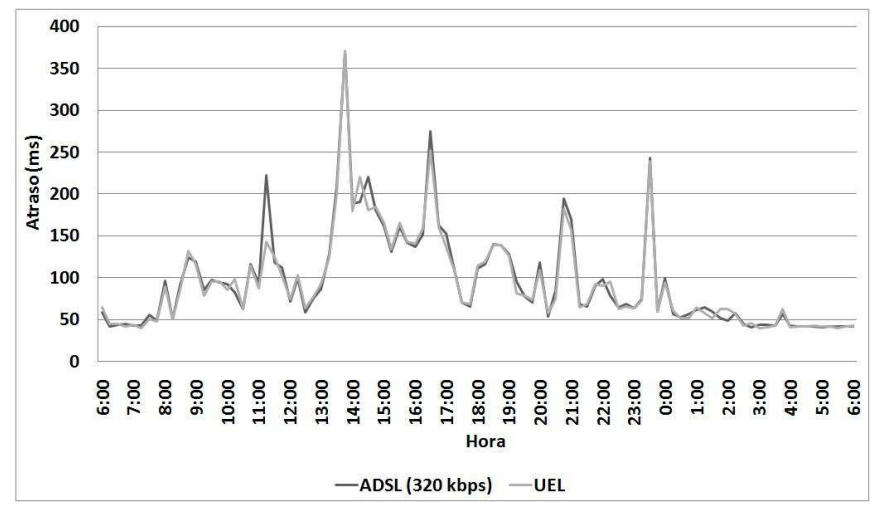

Fig. 5. Atraso médio na rede entre a UEL e uma conexão ADSL

A porcentagem de perda de pacotes que as ligações VoIP sofreram nesse mesmo cenário é apresentada na figura 6 . Também foi registrada uma perda maior nos períodos de maior utilização da Internet, porém não se observa uma relação tão próxima da qualidade com a perda de pacotes, pois em alguns momentos de perdas maiores não se vê uma queda significativa na qualidade. Outro fator representado nessa figura é a maior perda de pacotes por parte do usuário do ADSL. Essa perda maior se dá devido à menor largura de banda desse usuário, entretanto o gráfico de qualidade mostra que mesmo com essa diferença a qualidade fica bem próxima para ambos os usuários, já que os atrasos são próximos.

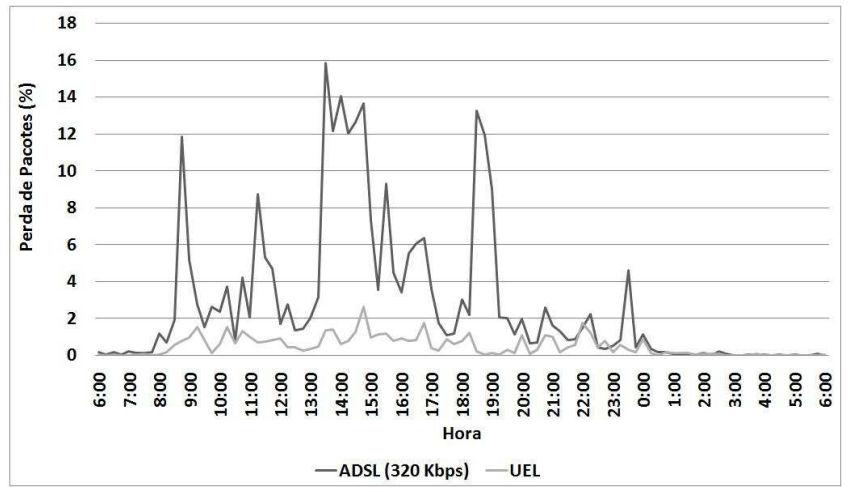

Fig. 6. Perda de pacotes média na rede entre a UEL e uma conexão ADSL

O segundo cenário de testes foi realizado entre a Universidade Estadual de Campinas (UNICAMP) e a UEL seguindo os mesmos parâmetros do teste anterior. A figura 7 ilustra o comportamento da qualidade percebida pelos dois pontos durante o período. Nesse cenário ainda é possível observar uma maior variação na qualidade apenas nos momentos de maior utilização da Internet, entretanto percebe-se que a qualidade é mais uniforme do que no cenário utilizando o ADSL. Durante quase todo o período é possível notar que a qualidade permanece boa com notas acima de 85 . Essa uniformidade no fator $\mathrm{R}$ desse cenário se deve ao fato de os dois locais possuírem links com alta largura de banda, permitindo melhores resultados no fator que mede a qualidade, mesmo que muitos usuários estejam utilizando a Internet, o que não pode ser observado no cenário com ADSL.

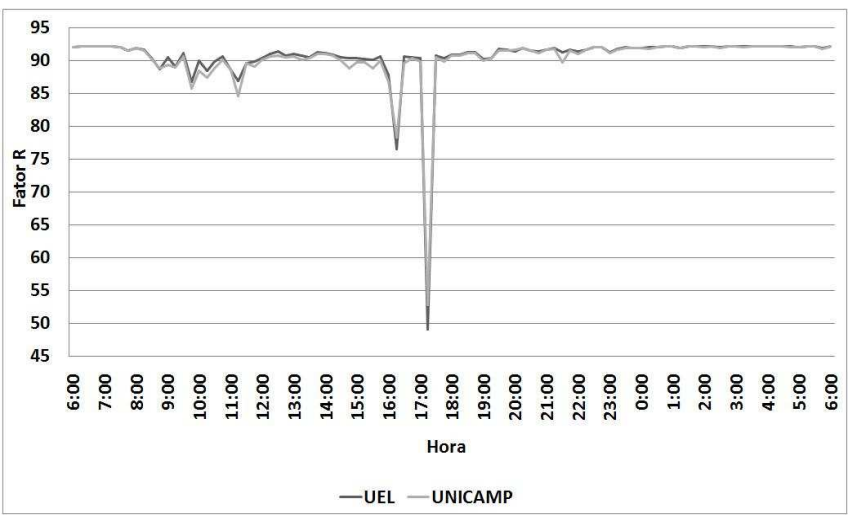

Fig. 7. Qualidade do VoIP entre a UEL e a UNICAMP

Apesar da melhora na qualidade das ligações, o teste também apresentou momentos em que as ligações VoIP não apresentaram qualidades satisfatórias, provavelmente devido a congestionamentos ocorridos na rede no momento da ligação. Pode-se observar que às $17 \mathrm{~h} 15 \mathrm{~min}$ obteve-se o fator $\mathrm{R}$ de 52,82 na UNICAMP e de 49,11 na UEL, revelando que nesse momento seria impraticável o VoIP entre esses locais. $\mathrm{O}$ gráfico da figura 8 demonstra como foi o atraso dos pacotes durante o dia de testes entre a UEL e a UNICAMP. O gráfico indica que os pacotes sofreram maior atraso nos momentos de maior utilização da Internet nas universidades e sofreram um atraso bem menor das $00 \mathrm{~h} 00 \mathrm{~min}$ às $08 \mathrm{~h} 00 \mathrm{~min}$, quando os links de Internet são pouco utilizados.

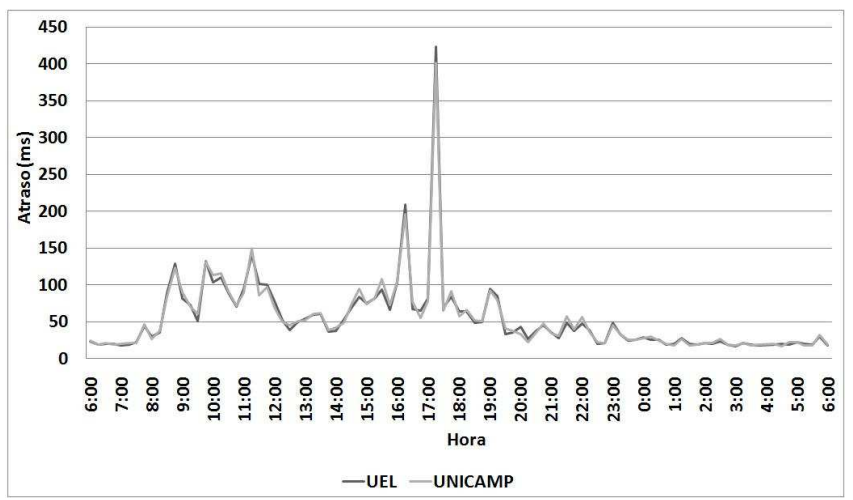

Fig. 8. Atraso médio na rede entre a UEL e a UNICAMP

No momento do dia que se observou a ligação com menor qualidade, expressada pelo fator R, às $17 \mathrm{~h} 15 \mathrm{~min}$, também foi registrado o momento de maior atraso na rede durante o dia, 401,98 ms na UNICAMP e 423,82 ms na UEL. É possível notar que a qualidade das ligações VoIP está diretamente relacionada ao atraso da rede, implicando em piora na qualidade à medida em que se tem atraso dos pacotes. De acordo com a figura 9, que representa a perda de pacotes média sofrida pelos usuários durante todo o período de testes, também há uma perda mais significativa nos momentos de maior utilização do link. Porém em alguns momentos é 
possível observar alguns picos de perdas e nesses mesmos momentos não há uma variação significativa da qualidade, indicando que o codec utilizado nesses testes tem uma boa aceitação à perda de pacotes. Utilizando codecs de qualidade inferior, uma pequena perda iria resultar em uma qualidade inferior à apresentada por esse codec.

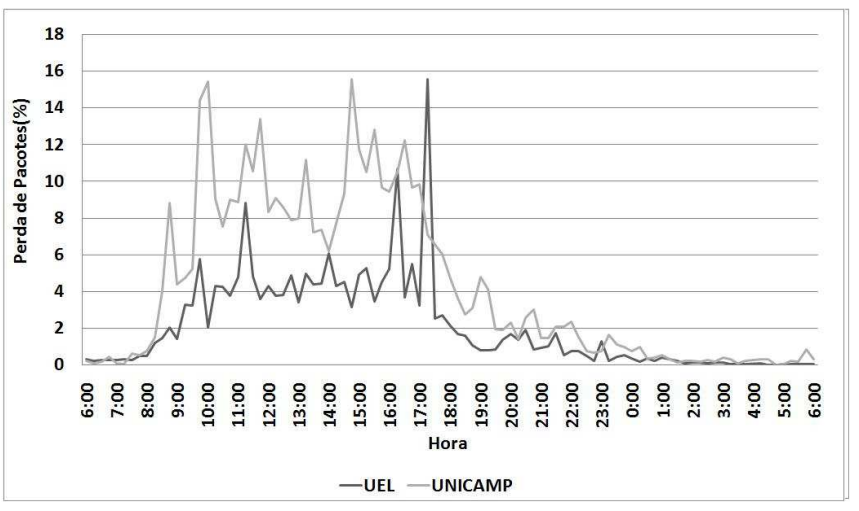

Fig. 9. Perda de pacotes média na rede entre a UEL e a UNICAMP

\section{CONCLUSÃO}

Os resultados apresentados demonstram que o modelo-E é um método muito eficaz para avaliar a qualidade de uma ligação VoIP. Ele possibilita que seja apresentado uma análise técnica da qualidade da ligação VoIP, possibilitando que usuários e provedores de serviços, de uma maneira simples visualizem resultados analíticos sobre a qualidade da ligação realizada. Também foi possível constatar que o aumento do tráfego na rede é inversamente proporcional à qualidade, pois acarretam variações significativas nos parâmetros que degradam a rede e que tem influencia direta sobre a qualidade de aplicações VoIP, como o atraso e a perda de pacotes.

Em trabalhos futuros deveremos alterar outras variáveis do modelo-E, como o codec e o tamanho do buffer de jitter, para que sejam analisados os efeitos que essas variáveis têm sobre a qualidade de ligações telefônicas utilizando o protocolo IP.

\section{AGRADECIMENTOS}

Os autores agradecem ao FINEP pelo apoio financeiro ao projeto Sistema para Monitoramento de VoIP - QVoIP.

\section{REFERÊNCIAS}

[1] J. C. Magro, "Estudo da qualidade de voz em redes IP", Dissertação de Mestrado, Departamento de Comunicações, Faculdade de Engenharia Elétrica e Computação, Unicamp, Campinas, 2005.

[2] F. D. Rango, M. Tropea, P. Fazio e S. Marano, "Overview on VoIP: Subjective and objective measurement methods", International Journal of Computer Science and Network Security, vol. 6, pp. 140-153, Jan. 2006.

[3] ITU-T G.107, The E-model, a computational model for use in transmission planning, 2004.
[4] ITU-T P.800, Methods for subjective determination of transmission quality, 2006.

[5] ITU-T P.861, Objective quality measurement of telephone-band (300-3400 hz) speech codecs, 1996.

[6] ITU-T P.862, Perceptual evaluation of speech quality (PESQ): An objective method for end-to-end speech quality assessment of narrow-band telephone networks and speech codecs, 2001.

[7] L. Carvalho, E. Mota, R. Aguiar, A. F. Lima, e J. N. de Souza, "An E-model implementation for speech quality evaluation in VoIP systems," 10th IEEE Symposium on Computers and Communications, pp. 933-938, 2005.

[8] A. D. Clark, "Modeling the effects of burst packet loss and recency on subjective voice quality," Columbia University IP Telephony Workshop, 2001.

[9]A. Passito, E. Mota, R. Aguiar, L. Carvalho, E. Moura, A. Briglia e I. Biris, "Using an E-model implementation to evaluate speech quality in voice over $802.11 \mathrm{~b}$ networks with vpn/ipsec," International Conference on Wireless Communications, vol. 2, no. 5, pp. 1123-1127, 2005.

[10] L. Ding and R. A. Gourbran, "Assessment of effects of packet loss on speech quality in VoIP," The 2nd IEEE Internatioal Workshop Audio and Visual Environments and Their Applications, pp. 49-54, July-Aug. 2003.

[11] K. M. McNeill, M. Liu e J. J. Rodriguez, "An adaptive jitter buffer play-out scheme to improve VoIP quality in wireless networks," Military Communications Conference, Oct. 2006.

[12] "Linphone, an open-source sip video-phone for linux and windows available at http://www.linphone.org.".

[13] F. David, "Ferramentas de monitoração ativa e passiva para avaliação da qualidade de redes VoIP," Dissertação de Mestrado, UFRJ, Rio de Janeiro, 2003.

[14] L. C. G. Lustosa, "Arquitetura de monitoração de qualidade de chamadas telefônicas IP,” Dissertação de Mestrado, UFRJ, Rio de Janeiro, 2005.

[15] L. C. G. Lustosa, L. S. G. Carvalho, P. H. de A. Rodrigues e E. de S. Mota, "Utilização do modelo e para avaliação da qualidade da fala em sistemas de comunicação baseados em Voz sobre IP," XXII Simpósio Brasileiro de Redes de Computadores (SBRC 2004), Maio, 2004.

[16] ITU-T G.114, One-way transmission time, 2003.

[17] ITU-T G.113 Appendix I, Provisional planning values for the equipment impairment factor Ie, 2007.

[18] ITU-TSG12, Estimates of ie and bpl parameters for a range of codec types, 2003.

[19] H. Schulzrinne, S. Casner, R. Frederick e V. Jacobson, "Rtp: A transport protocol for real-time applications," 2003.

[20] ITU-T G.109, Definition of categories of speech transmission quality, 1999. 